\title{
PENGARUH KEPUASAN PELATIHAN, DAN KETERLIBATAN KERJA TERHADAP NIAT BERPINDAH KARYAWAN (STUDI KASUS : PT. XYZ PERUSAHAAN JASA KONSTRUKSI SWASTA)
}

\author{
Yonathan Fernando Daiva \\ Program Studi Magister Manajemen Universitas Tarumanagara \\ YonathanFD@hotmail.com \\ Mukti Rahardjo \\ Program Studi Magister Manajemen Universitas Tarumanagara
}

Masuk : 21-11-2019, revisi : 04-12-2019 diterima untuk diterbitkan : 05-12-2019

\begin{abstract}
Human resources are an important role in the company's success in achieving its goals. without human resources, the company's goals will certainly not be achieved. employee turnover problems that will certainly be faced by every company. if the number of employee turnovers is high, of course this should be concern to the company so as not to hinder the achievement of company goals.

The purpose of this study was to determine the effect of training satisfaction, work involvement and turnover intention at PT. XYZ Private Construction Company. This research was conducted to employees at PT. XYZ. The sampling method uses Purposive Sampling. Data collection was carried out by distributing questionnaires to 59 respondents. And this type of research is quantitative and uses analytical methods with the SmartPLS 3.0 program.

The results showed that training satisfaction did not have a negative effect on turnover intention. Training satisfaction has a positive effect on work involvement. Work involvement has a negative influence on turnover intention. and there is a negative influence on job involvement mediating between training satisfaction and turnover intention.
\end{abstract}

Keywords : Satisfaction Training, Work Involvement, Turnover Intentions, Construction Companies.

Abstrak : Sumber daya manusia adalah faktor penting dalam keberhasilan perusahaan dalam mencapai tujuannya. tanpa sumber daya manusia, tujuan perusahaan tentu tidak akan tercapai. masalah turnover karyawan selalu akan dihadapi oleh setiap perusahaan. jika jumlah turnover karyawan tinggi, tentu ini harus menjadi perhatian agar tidak menghambat pencapaian tujuan perusahaan.

Tujuan dari penelitian ini adalah untuk mengetahui pengaruh kepuasan pelatihan, keterlibatan kerja dan intensi turnover pada PT. XYZ Perusahaan Jasa Konstruksi Swasta. Penelitian ini dilakukan terhadap karyawan di PT. XYZ dengan Metode pengambilan sampel menggunakan Purposive Sampling. Pengumpulan data dilakukan dengan menyebarkan kuesioner kepada 59 responden. Jenis penelitian ini adalah kuantitatif dan menggunakan metode analitik dengan program SmartPLS 3.0.

Hasil penelitian menunjukkan bahwa kepuasan pelatihan tidak memiliki efek negatif pada niat turnover. Kepuasan pelatihan memiliki efek positif pada keterlibatan kerja. Keterlibatan kerja memiliki pengaruh negatif terhadap intensi turnover. dan ada pengaruh negatif pada mediasi keterlibatan kerja antara kepuasan pelatihan dan intensi turnover.

Kata kunci : Pelatihan Kepuasan, Keterlibatan Kerja, Intensi Turnover, Perusahaan Jasa Konstruksi. 


\section{PENDAHULUAN}

Sumber daya manusia merupakan bagian penting dari perusahaan terutama di zaman era globalisasi ini banyak persaingan antara perusahaan yang semakin ketat dalam mencari karyawan yang mampu meningkatkan kinerja dan produktivitas perusahaan serta mampu bersaing dengan perusahaan lain. Jika terjadi tingkat perpindahan karyawan yang tinggi tentu sangat merugikan perusahaan seperti biaya yang sudah dikeluarkan perusahaan untuk mentraining karyawan tersebut, dibutuhkan biaya untuk rekrutment dan pelatihan kembali dan menjadikan aktifitas perusahaan tidak efektif (Perreyer et al, 2010 dalam Rombaut Evy, 2017).

Berangkat dari latar belakang tersebut, penelitian ini dilakukan dengan mengambil sample pada karyawan PT. XYZ ( Perusahaan Jasa Konstruksi Swasta ). Alasan dipilihnya PT.XYZ sebagai objek penelitian dikarenakan pengalaman penulis sendiri yang mengalami tingginya tingkat turnover karyawan pada tempat penulis bekerja, serta data turnover karyawan PT.XYZ yang relatif tinggi

\section{TINJAUAN KEPUSTAKAAN Kepuasan Pelatihan}

Pelatihan merupakan kegiatan sistematis dan terorganisir untuk memberikan pengetahuan, keterampilan dan keahlian yang diperlukan dalam pekerjaannya. Adanya pelatihan memberikan manfaat kepada karyawan dengan pengembangan pengetahuan dan keterampilan yang dibutuhkan dalam pekerjaan mereka secara efektif (Tamu dan Conway, 2006 dalam Tariq \& Qazi, 2014). Pelatihan merupakan kegiatan yang direncanakan oleh perusahaan memberikan pengetahuan mengenai hal yang berkaitan dengan pekerjaan dan mengembangkan keterampilannya untuk melaksanakan pekerjaannya dengan lebih baik demi meningkatkan kinerja perusahaan, komitmen perusahaan dan diharapkan menurunkan mengurangi perpindahan karyawan.

\section{Indikator Kepuasan Pelatihan}

Menurut Memon, Mumtaz Ali dkk, 2016 dapat diukur dengan 4 pertanyaan, yaitu:

1. Secara keseluruhan, pelatihan di tempat kerja, yang saya terima berlaku untuk pekerjaan saya.

2. Secara keseluruhan, pelatihan yang saya terima memenuhi kebutuhan saya.

3. Secara keseluruhan, saya puas dengan jumlah pelatihan yang saya terima.

4. Saya dapat menggunakan apa yang saya pelajari di pelatihan pada pekerjaan saya.

\section{Keterlibatan Kerja}

Keterlibatan kerja merupakan hal penting untuk dapat mengurangi adanya turnover. Jika keterlibatan kerja yang tinggi seorang karyawan akan mempengaruhi perilaku dan kinerja karyawan dan tentu tidak akan secara sukarela meninggalkan perusahaan. Menurut (Buckingham \& Coffman, 2005 dalam Artiningrum \& Aryana, 2016). Keterlibatan merupakan energi/ semangat seseorang dan jika karyawan turut aktif dan menghabiskan energi dalam karir dan pekerjaan mereka, maka mereka disebut terlibat. Keterlibatan kerja merupakan kegiatan seorang pekerja yang pastisipasi aktif dalam pekerjaannya dan menggangap kinerja penting bagi dirinya (Robbin, 2003 dalam Putri, Engla Dika. 2017).

\section{Indikator Keterlibatan Kerja}

Menurut Memon, Mumtaz Ali dkk, 2016 menyatakan terdapat 9 pertanyaan untuk mengukur tingkat keterlibatan kerja, sebagai berikut :

1. Ketika saya bangun pagi hari, saya merasa senang untuk pergi kerja.

2. Ditempat kerja saya, saya merasa penuh energi.

3. Pada pekerjaan saya, saya bersemangat dan tahan mental saat bekerja

4. Pekerjaan saya menginspirasi saya. 
5. Saya antusias tentang pekerjaan saya.

6. Saya bangga dengan pekerjaan yang saya lakukan.

7. Saya terlibat secara pribadi dalam pekerjaan saya.

8. Saya fokus dan merasa menikmati dalam pekerjaan saya

9. Saya merasa senang, ketika saya bekerja terus menerus.

\section{Niat Berpindah Karyawan}

Menurut Zeffane, 2009 dalam Annisa, Auliya. 2017 niat berpindah adalah keinginan karyawan untuk meninggalkan pekerjaan yang sekarang secara sukarela dan merupakan pilihan dari karyawan itu sendiri. (Harnoto, 2002 dalam Yunita, Ni Kadek Lisna. 2015) menyatakan niat perpindahan tingkat keinginan untuk keluar dari perusahaan tetapi belum ditunjukkan tindakan pasti meninggalkan perusahaan.

\section{Indikasi Terjadinya Turnover Intention}

Turnover Intention bisa ditandai adanya hal yang menyangkut perilaku karyawan antara lain: absensi karyawan, mulai malas bekerja, timbul keberanian untuk melanggar tata tertib dan perintah atasan, mulai adanya perubahan sikap dari biasanya.

\section{METODOLOGI PENELITIAN}

Penelitian Kuantitatif

Penelitian kuantitatif adalah suatu proses menemukan pengetahuan yang menggunakan data berupa angka sebagai alat menganalisis keterangan mengenai apa yang ingin diketahui (Kasiram (2008: 149) dalam bukunya Metodologi Penelitian Kualitatif dan Kuantitatif).

\section{Teknik Pengumpulan Data}

\section{Wawancara}

Penulis memperoleh data dengan wawancara langsung kepada karyawan PT XYZ ditempat penulis bekerja.

\section{Kuesioner}

Kuesioner adalah suatu teknik pengumpulan informasi yang memungkinkan analis mempelajari sikap-sikap, keyakinan, perilaku, dan karakteristik beberapa orang utama di dalam organisasi yang bisa terpengaruh oleh sistem yang diajukan atau oleh sistem yang sudah ada.

\section{Populasi dan Sampel Populasi}

Populasi dalam penelitian ini adalah 59 orang karyawan yang bekerja di PT. XYZ pada proyek dimana peneliti ditempatkan.

\section{Sampel}

Karena jumlah populasi pada penelitian ini tidak terlalu banyak, penulis mengambil seluruh populasi menjadi sampel (sample jenuh) yang berjumlah 59 orang.

\section{Metode Analisis}

Partial Least Square (PLS)

Salah satu SEM berbasis varian yang mulai banyak digunakan adalah PLS. Partial Least Square (PLS) adalah teknik statistika multivariate yang melakukan perbandingan antara variabel dependen berganda dan variabel independen berganda (Abdillah \& Jogiyanto, 2015). 


\section{Metode Statitiska}

Outer Model

Outer Model adalah model pengukuran yang digunakan untuk menilai validitas dan reabilitas model (Abdillah \& Jogiyanto, 2015). Perhitungan Outer Model terdiri dari 3 jenis yaitu Convergent Validity, Disriminant Validity atau AVE, dan Composite Validity.

\section{Inner Model}

Inner Model adalah Model structural yang digunakan untuk memprediksi hubungan kausalitas antar variabel laten. Melalui proses Boostraping, parameter uji T-Statistik diperoleh untuk memprediksi adanya hubungan kasusalitas. Perhitungan Inner Model terdiri dari dua jenis yaitu Koefisien Determinasi atau R Square dan T-Statistik.

\section{ANALISIS DAN PEMBAHASAN \\ Uji Korelasi}

Tabel 4.1

Uji Korelasi

\begin{tabular}{|l|r|r|l|}
\hline & $\begin{array}{l}\text { Kepuasaan } \\
\text { Pelatihan }\end{array}$ & $\begin{array}{l}\text { Keterlibatan } \\
\text { Kerja }\end{array}$ & $\begin{array}{l}\text { Niat } \\
\text { Berpindah }\end{array}$ \\
\hline Kepuasaan Pelatihan & 1,000 & & \\
\hline Keterlibatan Kerja & 0.732 & 1,000 & \\
\hline Niat Berpindah & -0.453 & -0.525 & 1,000 \\
\hline
\end{tabular}

Sumber : Hasil Pengolahan Data Primer dengan SmartPLS 3.0

Menurut Sugiyono (2007), hasil uji korelasi yang lebih besar dari 0,5 baik positif ataupun negatif memiliki pengaruh yang kuat antar variabel dan data yang lebih kecil dari 0,5 cenderung lemah pengaruh antar variabelnya. Pada hasil penelitian yang dilakukan variabel Kepuasaan Pelatihan mempengaruhi variabel Keterlibatan Kerja sebesar 0,732 sedangkan pengaruh variabel yang lemah pada variabel Kepuasaan Pelatihan terhadap niat berpindah yaitu sebesar $-0,453$.

\section{Uji Hipotesis}

Tabel 4.2

Path Coefficients

\begin{tabular}{|l|r|r|r|r|r|}
\hline & $\begin{array}{c}\text { Original } \\
\text { Sample } \\
(\mathbf{O})\end{array}$ & $\begin{array}{c}\text { Sample } \\
\text { Mean } \\
(\mathbf{M})\end{array}$ & $\begin{array}{c}\text { Standard } \\
\text { Deviation } \\
\text { (STDEV) }\end{array}$ & $\begin{array}{c}\text { T } \\
\text { Statistics } \\
(\mid \text { O/STDE } \\
\text { V|) }\end{array}$ & P Values \\
\hline $\begin{array}{l}\text { Kepuasaan } \\
\text { Pelatihan -> } \\
\text { Keterlibatan } \\
\text { Kerja }\end{array}$ & 0.732 & 0.733 & 0.076 & 9.676 & $\mathbf{0 . 0 0 0}$ \\
\hline $\begin{array}{l}\text { Kepuasaan } \\
\text { Pelatihan -> } \\
\text { Niat } \\
\text { Berpindah }\end{array}$ & -0.148 & -0.167 & 0.195 & 0.759 & $\mathbf{0 . 4 4 8}$ \\
\hline $\begin{array}{l}\text { Keterlibatan } \\
\text { Kerja -> Niat } \\
\text { Berpindah }\end{array}$ & -0.417 & -0.403 & 0.190 & 2.193 & $\mathbf{0 . 0 2 9}$ \\
\hline
\end{tabular}

Sumber : Hasil Pengolahan Data Primer dengan SmartPLS 3.0 
Tabel 4.3

Indirect Effect

\begin{tabular}{|l|c|c|c|c|c|}
\hline & $\begin{array}{c}\text { Original } \\
\text { Sample } \\
(\mathbf{O})\end{array}$ & $\begin{array}{c}\text { Sample } \\
\text { Mean } \\
(\mathbf{M})\end{array}$ & $\begin{array}{c}\text { Standard } \\
\text { Deviation } \\
\text { (STDEV) }\end{array}$ & $\begin{array}{c}\text { T } \\
\text { Statistics } \\
(\mid \mathbf{O} \text { /STDE } \\
\text { V|) }\end{array}$ & P Values \\
\hline $\begin{array}{l}\text { Kepuasaan } \\
\text { Pelatihan -> } \\
\text { Keterlibatan } \\
\text { Kerja }\end{array}$ & & & & & \\
\hline $\begin{array}{l}\text { Kepuasaan } \\
\text { Pelatihan -> } \\
\text { Niat } \\
\text { Berpindah }\end{array}$ & -0.305 & -0.292 & 0.140 & 2.175 & $\mathbf{0 . 0 3 0}$ \\
\hline $\begin{array}{l}\text { Keterlibatan } \\
\text { Kerja -> Niat } \\
\text { Berpindah }\end{array}$ & & & & & \\
\hline
\end{tabular}

Sumber : Hasil Pengolahan Data Primer dengan SmartPLS 3.0

Hasil nilai T-statistik dinyatakan signifikan jika memiliki angka lebih besar dari 1.96 dan dinyatakan tidak signifikan jika lebih kecil 1.96. Chin (1998) dalam Sarwono (2014: hlm. 23) Hipotesis 1 : Terdapat pengaruh positif antara kepuasaan pelatihan terhadap keterlibatan kerja.

Hipotesis 2 : Tidak terdapat pengaruh negatif antara kepuasaan pelatihan terhadap niat berpindah.

Hipotesis 3 : Terdapat pengaruh negatif antara keterlibatan kerja terhadap niat berpindah.

Hipotesis 4 : Terdapat pengaruh secara negatif variabel keterlibatan kerja memediasi antara kepuasaan pelatihan terhadap niat berpindah.

\section{KESIMPULAN} berikut:

Berdasarkan hasil penelitian yang dilakukan maka dapat ditarik kesimpulan sebagai

1. Hasil penelitian menunjukan kepuasan pelatihan tidak berpengaruh negatif dan signifikan terhadap niat berpindah di PT. XYZ karena memiliki nilai T-Statistik kurang dari $1,96(0,763<1,96)$ hal ini didukung oleh penelitian yang dilakukan oleh Budi Arthiningrum (2016) yang melakukan riset pada karyawan perbankan.

2. Hasil penelitian menunjukan kepuasan pelatihan berpengaruh positif dan signifikan terhadap kepuasan pelatihan dengan keterlibatan kerja di PT. XYZ karena memiliki nilai T-Statistik lebih dari 1,96 $(9,828>1,96)$ dan hasil penelitian ini mendukung penelitian sebelumnya oleh Memon, Mumtaz Ali dkk, 2016

3. Hasil penelitian menunjukan keterlibatan kerja berpengaruh negatif terhadap niat berpindah di PT. XYZ karena memiliki nilai T-Statistik lebih dari 1,96 (2,079>1,96) dan hasil penelitian ini mendukung penelitian sebelumnya oleh Memon, Mumtaz Ali dkk, 2016

4. Hasil penelitian menunjukan terdapat pengaruh negatif keterlibatan kerja terhadap kepuasan pelatihan dan niat berpindah di PT. XYZ karena memiliki nilai T-Statistik lebih dari 1,96 $(2,081>1,96)$ dan hasil penelitian ini mendukung penelitian sebelumnya oleh Memon, Mumtaz Ali dkk, 2016 


\section{DAFTAR PUSTAKA}

Abdallah, Ayman Bahjat. 2017. "An Integrated Model of Job Involvement, Job Satisfaction and Organizational Commitment: A Structural Analysis in Jordans's Banking Sector". Communication and Network, 2017, 9, 28-53.

Abdillah, Willy \& Jogiyanto. 2015. "Partical Least Square (PLS) Alternatif StructuralEquation Modeling (SEM) dalam Penelitian Bisnis”. Yogyakarta : Penerbit Andi.

Elfrianto. 2016. “Manajemen Pelatihan Sumber Daya Manusia dalam Meningkatkan Mutu Lulusan" Jurnal Edutect, Vol. 2, No. 2.

Memon, Mumtaz Ali dkk. 2014. "Person-Organization Fit and Turnover Intention : The Mediating Role Of Employee Engagement". Global Bussiness and Management Research: An International Journal Vol, 6, No. 3.

Memon, Mumtaz Ali dkk, 2016. "The Link Between Training Satisfaction, Work Engagement and Turnover Intention"

Memon, Mumtaz Ali dkk. 2017. "The relationship Between Training Satisfaction, Organisational Citizenship Behaviour, and Turnover Intention".

Nazir, Moh. 2014. Metode Penelitian. Jakarta : Ghalia Indonesia.

Sugiyono. 2017. Statistika untuk Penelitian. Bandung : Alfabeta 